\title{
Retrospect and Prospect of 30 years' Development of Mental Health Education in Chinese Colleges and Universities
}

\author{
Tao Jin \\ Zhejiang University, \\ Zhejiang University of Technology, \\ Zhejiang, China
}

\author{
Ma Jianqing \\ Zhejiang University, Zhejiang, China
}

\begin{abstract}
The purpose of this paper is to propose strategies to advance the development of mental health education in colleges and universities with times. Through adopting literature research and history research, this paper reviews 30 years' development experience of mental health education in Chinese colleges and universities in five aspects, including education concept, education content, education mode, work team and scientific research. Besides, it reflects the problems and difficulties that have not been solved in the development process. Thus, this paper attempts to put forward the future development trend of mental health education in colleges and universities, including localization, specialization, popularization and informatization.
\end{abstract}

Keywords-Colleges and Universities; Mental health education; Development experience; Development trend

\section{INTRODUCTION}

In the mid-1980s, with the rapid development of politics, economy and the tide of education reform, China's mental health education in colleges and universities started. It has been developing for 30 years, experiences a tremendous progress from scratch. The mental health education in colleges and universities has played an active role in alleviating psychological pressure of undergraduates and improving their psychological quality. However, there are still some problems and difficulties. Therefore, reviewing the 30 years development experience, reflecting on the shortcomings and analyzing future development trend, these are the internal needs of developing mental health education theory with Chinese characteristics and the urgent needs to achieve a leap-forward development of mental health education in Chinese colleges and universities.

\section{RETROSPECT}

\section{A. The concept has changed from problem-centered to human-centered, but there is still a cognitive gap}

Educational concept is based on practice of educational theory and reality of social development, reflecting the subject's rational understanding of educational essence and its natural pursuit. The development of mental health education in China implies a change from problem-centered to humancentered. From 1987 to 2000, China's reform and open policy led to a fast growth of economy, science, technology and culture. More and more scholars in universities were paying attention to the study of mental health problems. It went through the process of spontaneous offering optional courses of mental health education and psychological counseling services in few schools, to constructing and developing school-level psychological counseling centers in most colleges and universities. However, the service target was mainly a minority of students with psychological problems, while the vast majority of students with developmental problems were ignored. In 2001-2011, the Ministry of Education issued a document on Strengthening Mental Health Education for Colleges and Universities' Students in 2001, which clearly request schools create conditions to offer optional courses or experts lectures and reports on mental health education. With the gradual popularization of mental health knowledge, mental health consciousness of university students has been continuously improved, and they have gradually begun to pay attention to their own mental health. However, due to different regional attention, inadequate work norms and low level of team specialization, in most universities and colleges, student work department is responsible for this work. In recent years, suicide and other extreme incidents caused by psychological problems occurs frequently, whereas, colleges and universities often assess by quantitative indicators which makes the emphasis of education is still on the screening and intervention of serious psychological problems. It is difficult to actually implement the educational concept of people-centered. With the increasing emphasis on mental health issues in the country, relevant education policies have been formulated and issued continuously, and the popularity of undergraduate mental health education has been constantly improved. In January 2017, National Health and Family Planning Commission and other 22 departments jointly issued the document of Guidance on Strengthening Mental Health Services, putting forward the principle of prevention first and people first. It requires colleges and universities implement mental health curriculum construction, pay more attention to school, family and society, which jointly carry out mental health education promotion activities, attach importance to psychological crisis intervention as well as improve psychological quality and potential development of all students. 


\section{B. The content has developed from emphasis on disorder correction to close to life, but the content is not systematic enough}

The reasonable selection of mental health education content is undoubtedly the key link in the implementation of mental health education in colleges and universities. There are mainly three basis: the goal of mental health education is the direct basis, the age characteristics of students and their psychological development level are the essential basic, the present situation and the actual situation of students' mental health are the realistic basis [1]. In the early development stage of mental health education in colleges and universities in the late 1980s, psychological counseling organizations were established successively. In 1989, the State Education Committee investigated 126,000 undergraduates and found that $20.23 \%$ of them had psychological disorders [2]. But there are few students who come to consult actively, accounting for only about $1-2 \%$ [3]. Mainly because students were still very unfamiliar with psychological counseling and psychological counseling mainly focused on serving minority with serious psychological problems at that time. Therefore, the initial content of mental health education for students was mainly to popularize mental health knowledge and concepts, as well as carry out psychological disorder treatment. With students' increasing consciousness of mental health and the popularization of psychological counseling services, the content of mental health education is gradually close to life. With the new situation of university enrollment expansion and employment marketization occurred in the 21 st century, the content of mental health education had been further developed and deepened, which mainly involved undergraduate love and marriage, employment psychology, network psychology and potential development, etc. The survey of some colleges and universities conducted by Nanjing Crisis Intervention Center in 2005 showed that the student suicide rate reached $0.02 \%$, twice as high as the national natural rate. The cold fact highlighted undergraduate's disregard and contempt for life. Especially after The CPC Central Committee and State Council on further Strengthening and Improving the Ideological Politics of College and University Students, life education, as a new trend of thought, has already emerged quietly. It explores life problems caused by interpersonal confusion, pessimism, indifference to life, spiritual emptiness, and pays attention to the content that mental health education has not focused on. As the changing of time, researchers continue to supplement and refine the content of mental health education. The content that scholars proposed is very detailed, but most of them are from the perspective of theoretical speculative research, lacking empirical research on the evaluation and feedback of educational content by education objects. Although the content of education involves nearly every aspects of student life, on the whole, the content of psychological education seems fragmented and lack of systematization.

\section{The mode has changed from explicit education to combination with explicit and implicit, but the implementation effect is dissatisfactory}

The mode of mental health education mainly includes explicit education and implicit education. Explicit education has clear educational aims, requirements and contents, including mental health curriculum education, psychological counseling and mental health propaganda activities. Implicit education is another mode through potential education factors indirectly shape and influence education object's psychology, emotion and personality [4]. In China, mental health education mode has experienced long years developing, changing from explicit education to combination education with explicit and implicit. From 1987 to 2000, universities mainly provided oneto-one individual psychological counseling services, and a small number of schools spontaneously offer optional courses on a small scale. From 2001 to 2010, the number of schools with individual counseling services was continuously increasing, group counseling and peer counseling emerged. More and more colleges and universities were offering optional courses influenced by the government policy, and popularized psychological knowledge and enhanced undergraduate mental health consciousness by special lectures, reports and propaganda materials. From 2011 to the present, psychological counseling has developed into a mode used multiple approaches, such as psychological counseling, psychological tests and psychological training. In 2011, the Ministry of Education promulgated the Basic Requirements for Teaching Mental Health Education Courses for College and University Students, which clearly put forward that mental health education compulsory courses should be offered and be taken as main channel in colleges and universities. It marked that China's mental health education would enter a new mode of large scale compulsory courses offered in colleges and universities. Moreover, by using various potential education factors, such as campus culture construction, dormitory psychological field construction and extracurricular practice activities, mental health education implements permeating education, to help nurturing and shaping student's psychology, personality and emotion, and create a favorable environment for student's mental health development. After 30 years of development and exploration, we have basically formed a combination mode of explicit education and implicit education, which diversified education methods by closely combination among in-class and out-of-class education, consultation and self-education, teaching and guidance. But in practice, the development level in different university is still uneven, presenting a condition that universities tend to use individual counseling rather than group counseling, offer mental health curriculums rather than psychological training activities, use psychological test results rather than scientific analysis. Secondly, the methods of mental health education are not advanced and scientific enough. Most colleges and universities fail to popularize foreign psychological techniques, and lack necessary technical equipment for psychological counseling. Finally, because the existing higher education can't actively adapt to social development and satisfy undergraduate's physical and mental development needs, with teachers' relatively mechanical teaching methods, mental health 
education is hard to truly organically permeate courses of daily teaching.

\section{With participants from various fields, the team has grown from weak to strong, but the degree of specialization is not high enough}

Undergraduate mental health education is a highly professional work. With the increasing demand, the quantity and the quality of team has become the key to decide if colleges and universities mental health education can effective promote and make a breakthrough development. In the initial stage, mental health education team in colleges and universities mainly came from medical staff, teachers of psychology and education, and counselors. But the number was small and the quality was not high, and they were in a state of learning while doing, the overall strength was relatively weak. From 1987 to 1990, Peking University, Renmin University of China, Central China Normal University and other universities spontaneously held many training courses on psychological counseling theory and practice for teachers. Since then, psychological advisory committees of mental health associations have been set up in colleges and universities around the country, through various ways, such as psychological counseling case seminars, mental health scientific research, evaluation of psychological counseling, professional qualification evaluation of psychological consultants and psychological counseling supervisor system, to strengthen the professional construction of team. With years of development, the strength of team has gradually grown. At present, most colleges and universities are equipped with mental health teachers as required by the Ministry of Education. In general, there is 1-2 full-time staff for mental health education at the school level, the rest parttime staff is mainly composed of university's counselors, psychological teachers, medical personnel, etc. However, there are some imbalances among colleges and universities, and the overall specialization degree is still not high. There are fewer full-time staff and more part-time staff, and the establishment post only for mental health education is not implemented yet, full-time post for mental health education has not fully realized. Many mental health centers in colleges and universities are subordinate to student affair departments, so full-time staffs of mental health education are also busy with administrative affairs. At the same time, school counselors as the majority of team, lacking professionalism and busy with daily affairs, seriously affects their engagement and effect for mental health education works. In addition, according to the requirement of the Ministry of Education in 2011, colleges and universities need a large number of professional teachers to offer mental health education compulsory courses. The survey in Zhejiang Province shows, the proportion of teachers with intermediate titles is more than $82 \%$, which is probably the lowest in all the courses in colleges and universities. Even in some vocational colleges, all the teachers who teach this course are lecturers and assistants [5]. Therefore, low professionalization, low full-time and low professional title rate, actually restrict the development of mental health education popularization, which is still an urgent problem to be solved.

\section{E. The scientific research achievements increased for years to a plateau, but lack of high quality and localization results}

In the initial stage, mental health education in colleges and universities was mainly by practice, and the theoretical research was less. With an increasing attention paid by government and academia, the number of published papers increases year by year, but as a whole the amount is small. In 1998, Professor Ma Jianqing pointed out, $61.5 \%$ of the papers about undergraduate mental health education in Chinese Mental Health Journal were assessments or comparative studies of different types of undergraduate. The research field was relatively wide, but most of them focused on the assessment of university student's mental health condition or mental health work research, the published papers mainly focused on introducing theoretical methods and practical experience of foreign countries, and the research showed a relatively divided mode of empirical research and speculative research. In 2005, the Ministry of Education established National Expert Guidance Committee on Mental Health Education, to conduct function of research, consultation, evaluation and guidance on undergraduate mental health education. Government's highly emphasis powerful propelled the progress of theoretical research on mental health education. A large number of national and provincial level research projects have been carried out successively. Monographs and textbooks with the contents of undergraduate mental health and psychological counseling have been published one after another. According to incomplete statistics, 200 books on mental health education have been published. But there are also problems and hidden troubles behind the current research prosperity. First, the research is more fragmented, not systematic, not forming a complete theoretical system. Second, the research has a low starting point and more repetitive achievements, but local research with deep and creative breakthrough is rare. Third, empirical research and speculative research has rarely integrated, some speculative research methods are not scientific, and empirical research lacks humanistic care. Four, there is a lack of vertical historic research about its development regularity. Fifth, there are very few high quality psychological tests designed for Chinese students. Sixth, discipline construction strength is insufficient, and reserve force of theoretical research is inadequate. On the whole, scientific research is at a plateau, the research quality has to improve and break through.

\section{PROSPECT}

The theoretical system and practical exploration of mental health education in China are deepening and advancing. With the internal development demand of new social environment and theoretical system, the author believes development trend of mental health education in colleges and universities are localization, specialization, popularization and informatization. 


\section{A. Localization: creative inheritance and development of Chinese characteristics mental health education theory}

Mental health education is the inheritance and transcendence of Chinese traditional culture. It contains rich mental health thoughts, for example, ideal personality of becoming adults in Confucian culture reflected characteristics of mental health personality, and ancient physicians used emotional therapy to do treatment. Therefore, developing empirical research based on traditional culture and traditional Chinese medicine and forming clinical psychological counseling services with Chinese characteristicit will be an important direction for localization. Moreover, mental health education is an important way to improve ideological and political education in colleges and universities, their continuous integration and development is the course of localization. Mental health education use scientific method to improve individual function of ideological and political education, while mental health education needs further concise features in content, objectives, models and methods. Finally, on the basis of national condition, historical tradition and national psychology, we should creatively reform and apply the advanced technology and successful experience of foreign mental health education, through theory transformation, pilot application, re-transformation and re-application to establish a mental health education system with Chinese characteristics.

\section{B. Specialization: continuously upgrading the professionalization of mental health education team}

Talents are the core factor for enhancing effectiveness of mental health education in colleges and universities. Therefore, the most important thing is to strengthen the professional construction of team. Specifically, discipline development will be strongly strengthened, gradually set up psychological counseling major in prepared school, and nurture and construct a batch of practical teaching demonstration bases to drive the discipline construction, in order to provide continuous reserve force for mental health education developing. And then, we shall establish a professional, systematic and long-term training mechanism, cultivate mental health teachers as expert training, gradually form a talent training system combining academic education, post-graduation education and continuing education, and promote to form a long-term education mechanism for the existing full-time and part-time work team. Finally, the certification of professional team will be more standardized. We should improve professional level of psychological counselors training institutions and certification institutions, establish practical supervision system relying on qualified and reputable medical institutions, universities, scientific research institutes, etc., set up certification system of qualifications, and strictly check and periodically examine the relevant qualifications of training institutions, certification institutions and supervisory institutions.

\section{Popularization: overall popularize mental health education with emphasis on both developmental concept and preventive concept}

In recent years, individual extreme events caused by undergraduate psychological problems are frequently happened. So we still need to strengthen the overall popularization of mental health education, continuously enhance mental health self-management consciousness, strengthen humanistic care and life education. The concepts of people-oriented and prevention-oriented will guide the direction of the comprehensive popularization of mental health education. The target group of mental health education in colleges and universities will be further broadened, from students to teachers, managers and even parents of students. Meanwhile, the concepts and techniques of mental health education will be applied in daily teaching. The network system of four-level psychological crisis intervention in schools, departments, classes and dormitories will be more sound and powerful. In order to minimize the occurrence of extreme events, and promote college student's psychological function, cultivate their good psychological quality and healthy personality.

\section{Informatization: mental health education new ways rise under the background of micro-media and big data}

In the information age, the popularity of micro-media such as microblog and wechat has broken the time and space barrier of information exchange, brings a brand-new mode of interpersonal interaction. In the future, if mental health education in universities wants to keep pace with the times and have a breakthrough, it will be necessary to establish a tridimensional and systematic mechanism of mental health education network. It needs to further strengthen the propaganda and education function by micro-media, develop psychological counseling service based on micro-media, and carry out two-way interactive education mode of online and offline. In addition, in the era of big data with education reform, whoever occupies the big data of education will grasp the future of education [6]. Big data will make great changes in the way of thinking and research methods of mental health education. For example, it is impossible for traditional mental health education to monitor every student's mental health continuously. Whereas, by collecting and updating big data, and through logical reasoning of college student's daily data, making association analysis and massive data statistics, it can master their daily studying status, living status and emotional status, to provide support for the establishment of effective prediction and prevention mechanism of mental health education in colleges and universities.

\section{ACKNOWLEDGMENT}

This paper is the phased result of 30 years study on the combination of mental health education and ideological \& political education, which is identified as the Ministry of Education's humanities and social science research and planning fund project in 2016.

Corresponding author: Tao Jin, doctoral candidate at Zhejiang University, Lecturer of Zhejiang University of Technology. 


\section{REFERENCES}

[1] Ye yituo, Research on mental health of modern schools, Beijing: kai Ming press, March 2003. (In Chinese)

[2] Ma Jianqing, "Situation and tasks of undergraduate psychological counseling," November 1990. (In Chinese)

[3] Fan Fumin, "Review and prospect of psychological counseling activities in Chinese universities," Youth Research, April 1993. (In Chinese)

[4] Lu Aixin, "The research on the development of China's undergraduate mental health education," doctoral dissertation of Central China Normal University, p.91, 2007. (In Chinese)

[5] Ma Jianqing, "The process and thinking of 30 years construction of mental health education course for Chinese undergraduate," Journal of Ideological and Theoretical Education, November 2016. (In Chinese)

[6] Chen Tan, National governance in the age of big data, Beijing: China Social Sciences Press, 2015, p.163. (In Chinese) 